\title{
Safe working practices and HIV infection: knowledge, attitudes, perception of risk, and policy in hospital
}

\author{
Gillian Davidson, Pamela Gillies
}

\begin{abstract}
Objectives-To assess the knowledge, attitudes, and perceptions of risk of occupational HIV transmission in hospital in relation to existing guidelines. Design-Cross sectional anonymous questionnaire survey of all occupational groups.

Setting-One large inner city teaching hospital.

Subjects-All 1530 staff working in the hospital in October 1991 and 22 managers.
\end{abstract}

Main measures-Knowledge of safe working practices and hospital guidelines; attitudes towards patients with AIDS; perception of risk of occupational transmission of HIV; availability of guidelines.

Results-The response rate in the questionnaire survey was $63 \%(958 / 1530)$. Although staff across all occupational groups knew of the potential risk of infection from needlestick injury $(98 \%$, 904/922), significantly more non-clinical staff (ambulance, catering, and domestic staff) than clinical staff (doctors, nurses, and paramedics) thought HIV could be transmitted by giving blood $(38 \%, 153 / 404$ $\left.v 12 \%, 40 / 346 ; \chi^{2}=66.1 \mathrm{p}<0.001\right)$; one in ten clinical staff believed this. Except for midwives, half of staff in most occupational groups and 19\% (17/91) of doctors and $22 \%(28 / 125)$ of nurses thought gloves should be worn in all contacts with people with AIDS. Most staff $(62 \%, 593 / 958)$, including $38 \%$ (36/94) of doctors and $52 \%(67 / 128)$ of nurses thought patients should be routinely tested on admission, $17 \%$ of doctors and $19 \%$ of nurses thought they should be isolated in hospital. One in three staff perceived themselves at risk of HIV. Midwives, nurses, and theatre technicians were most aware of guidelines for safe working compared with only half of doctors, ambulance, and paramedical staff and no incinerator staff.

Conclusions-Policy guidelines for safe working practices for patients with HIV infection and AIDS need to be disseminated across all occupational groups to reduce negative staff attitudes, improve knowledge of occupational transmission, establish an appropriate perception of risk, and create a sup- portive and caring hospital environment for people with HIV.

Implications-Managers need to disseminate policy guidelines and information to all staff on an ongoing basis.

(Quality in Health Care 1993;2:21-26)

\section{Introduction}

Most of the very few cases of transmission of HIV from patients to health care workers in an occupational setting have been due to sharps or needlestick injuries. ${ }^{1}$ The risk of transmission from a single inoculation injection continues to remain extremely small, of the order of $0.35 \%$ or 1 in 275 such inoculations. ${ }^{2}$ Guidelines for safe working practices in relation to transmission of HIV in health care settings are nonetheless important as they aim at informing, inculcating a realistic perception of the risk of occupational infection with HIV, and supporting positive attitudes towards treating people with HIV infection and AIDS. ${ }^{3}$

Few would argue that having well informed health care staff is not important. Although knowledge of safe working practices may not guarantee application of safe procedures, ${ }^{4}$ better informed nurses are more likely to hold favourable attitudes towards patients with HIV and their care. ${ }^{5}$ Surveys of knowledge about safe working practices and routes of transmission of HIV show that doctors and nurses tend to have a relatively high level of knowledge, particularly concerning the use and disposal of sharps and needles. ${ }^{4-10}$ Akinsanya and Rouse, however, recently showed some prevailing misconceptions about HIV transmission among hospital nursing staff and suggested that more information and further training are needed. ${ }^{9}$ One in three hospital nurses in England thought that HIV could be transmitted by donating blood and one in ten that there was a risk of infection from sharing cutlery with an infected person. ${ }^{9}$ In a study of all clinical and non-clinical administrative staff in Hampstead health authority $65 \%$ of staff expressed a need for information on HIV and AIDS, ${ }^{10}$ which fell to $40 \%$ after educational material had been distributed to all staff.

Many studies of health care workers have disclosed negative attitudes towards patients with AIDS. ${ }^{51-15}$ Among hospital staff in the United States, including technical and laboratory staff, therapists, orderlies and porters, messengers and social services 
workers, as well as doctors and nurses, Pleck et al found a high prevalence of negative attitudes and "AIDS phobic attitudes," particularly among those with the least contact with people with AIDS.$^{13}$ As the World Health Organisation has noted ${ }^{16}$ the management, care, and treatment of people with AIDS requires understanding, tolerance, and avoidance of stigmatisation or ostracisation. The effective and caring management of patients with HIV infection or AIDS in hospital may therefore depend, in part, on a supportive environment in the widest sense, involving all staff.

About one in four clinical and non-clinical or administrative health authority $\operatorname{staff}^{10}$ and one in three nurses ${ }^{9}$ respectively think that there is a risk of acquiring HIV infection in the workplace. Inappropriate perceptions are important in that they affect the way in which patients with HIV and AIDS are treated by hospital staff. ${ }^{11}$ 13 Such data have led the United Kingdom Central Council of Nursing, Midwifery, and Health Visiting to reiterate that the risk of occupational HIV transmission is slight and that nurses cannot and should not be selective about the categories of patients for whom they will care. ${ }^{17}$

We report a large scale study of the knowledge, attitudes, and perceptions of risk of occupational HIV transmission of all occupational groups in one hospital. It is unusual in that it aims at placing the findings within the context of existing guidelines for safe working. It also documents the views of senior managers and staff and considers the implications for policy and practice.

\section{Methods}

The study was designed in two phases: the first phase was a questionnaire survey of all hospital staff from all occupational groups at Queen's University Hospital in October 1991, and the second phase was an interview survey of all senior managers of the 22 hospital departments during October-November 1991.

QUESTIONNAIRE SURVEY

All 1530 staff present on a single working day in each of the hospital departments were asked to complete a cross sectional, anonymous, self completed questionnaire. The questionnaire was derived from questionnaires used in previous UK studies ${ }^{\circ 10}$ and included questions on personal details such as age, sex, occupation, and length of employment and, in relation to HIV and AIDS, the information and training received, knowledge of hospital policy, perception of risk of infection to self and to other groups of hospital staff, attitudes towards patients with HIV, and knowledge of HIV and its routes of transmission in hospital. Staff were also asked if they thought they could become infected from "sharing cutlery with someone with HIV" and "giving a blood donation" (both true or false).

The answers to two of the questions were compared to assess internal reliability (consistency) of response. ${ }^{18}$ In the first question (question 3) respondents were asked to tick their job category and in the second (question 4) to describe their work. A one in ten random sample of the completed questionnaires was selected (with a code number from an inhouse random number generator program), and the two questions in this sample were compared. In the 96 questionnaires sampled $89(93 \%)$ of the questions compared exactly, five $(5 \%)$ gave answers that could not be assessed for comparison, and two (2\%) were not comparable. These data indicate that response to the questionnaire was reliable in the area studied. The response to other more sensitive questions may also be reliable but cannot be guaranteed; at least three matched pairs of questions are advisable for assessing reliability, but the length of the questionnaire precluded this. A pilot study was however undertaken with a volunteer mixed sample of 52 staff from a hospital in another city, and questions were found to be acceptable when assessed for clarity and ambiguity.

The senior managers of each of the departments (total 15 occupational groups) disseminated the anonymous questionnaires, which were completed by the staff on one working day in October 1991. Completed questionnaires were returned by the respondents in sealed envelope through a secure box in the department. Response rates were calculated according to the number of completed scripts returned on the day divided by the number of staff at work on that day, which was determined for each department within one to two days after completion of the survey.

The data were analysed with the Statistical Package for the Social Sciences computer program.

INTERVIEW SURVEY

One researcher (GD) carried out a structured interview with each of the 22 senior managers. The decision to interview only heads of hospital departments was due to resource constraints. We acknowledge that ward sisters, senior technicians, and other staff in middle management have an important management role. None of the senior managers refused to participate. Before the survey the unit general manager of the hospital had advised them all of the survey and encouraged their participation.

The interview took its form from the questionnaire and included items on training related to HIV infection and AIDS, availability of policy guidelines, and their dissemination to staff; it took 30 minutes to complete. Ethical approval for the study was obtained from the ethical committee of Queen's Medical Centre, University Hospital, Nottingham.

\section{Results}

QUESTIONNAIRE SURVEY

A total of 958 staff of 1530 in the sample responded to the questionnaire, giving a response rate of $63 \%$. The rate varied by occupational group, with the highest being achieved among domestic staff, ward staff, and 
midwives and the lowest among ambulance staff (table 1).

Routes of HIV transmission - Most staff knew that there was a risk of HIV infection after a needlestick injury with a needle with blood contaminated with HIV (98\%, 904/922). However, almost one in four $(23 \%, 221 / 941)$ thought there was also a risk from donating blood. Significantly more non-clinical staff such as ambulance, catering, clerical, domestic, and portering staff held this view than clinical staff such as doctors, nurses, and paramedics (38\%, 153/404 v 12\%, 40/346; $\left.\chi^{2}=66 \cdot 1, p<0 \cdot 001\right)$. Nearly one in ten of all staff thought HIV could be transmitted through sharing cutlery used by a person infected with HIV $(12 \%, 75 / 921)$, and significantly more catering (28\%, $7 / 25)$, domestic $(20 \%, 27 / 137)$, and ambulance $(15 \%, 10 / 67)$ staff than all other groups combined thought sharing cutlery a possible route for transmission $(19 \%, 44 / 229 v 6 \%$, 45/703; $\left.\chi^{2}=34.9, \mathrm{df}=1, \mathrm{p}<0.001\right)$.

Use of gloves - Most staff knew that gloves should be worn when handling body fluids from patients with HIV and when cleaning hospital toilets. With the exception of midwives, who were extremely well informed about appropriate use of gloves, high proportions of all other staff stated that gloves should be worn during all contacts with people with HIV infection and AIDS (table 2).

Awareness of guidelines for safe working Regardless of occupational grouping, most

Table 1 Response rates to questionnaire by hospital department

\begin{tabular}{lc}
\hline Occupational group & No (\%) of respondents* \\
\hline Ambulance $(n=200)$ & $67(34)$ \\
Catering $(n=38)$ & $25(66)$ \\
Domestic $(n=153)$ & $137(90)$ \\
Incinerator $(n=7)$ & $5(71)$ \\
Laboratory $(n=261)$ & $170(65)$ \\
Medical records $(n=150)$ & $94(63)$ \\
Medical equipment services unit & $34(57)$ \\
$\quad(n=60)$ & $9(75)$ \\
Midwife $(n=12)$ & $129(63) \ddagger$ \\
Paramedic $(n=205)$ & $36(60)$ \\
Porter $(n=60)$ & $30(70)$ \\
General technical and theatre & \\
technical $(n=43)$ & $98(58)$ \\
Theatre ${ }^{+}(n=169)$ & $124(72)$ \\
Wards ${ }^{+}(n=172)$ & $958(63)$ \\
\hline Total $(n=1530)$ &
\end{tabular}

^Not all questions were completed by each respondent. +Includes consultants, other grades of doctor, and nurses. $\ddagger 14$ Paramedics answered part of questionnaire.

Table 2 Number (percentage) of respondents stating use of gloves in all contacts with patients with HIV or AIDS, by occupational group

\begin{tabular}{lc}
\hline Occupational group & No (\%) \\
\hline Ambulance $(n=67)$ & $49 / 67(73)$ \\
Catering $(n=25)$ & $17 / 23(74)$ \\
Clerical $(n=139)$ & $76 / 133(57)$ \\
Doctor ${ }^{+}(n=94)$ & $17 / 91(19)$ \\
Domestic $(n=137)$ & $111 / 135(82)$ \\
Incinerator $(n=5)$ & $4(80)$ \\
Laboratory $(n=139)$ & $63(45)$ \\
Medical equipment services unit $(n=34)$ & $18(53)$ \\
Midwife $(n=9)$ & 0 \\
Nurse $(n=128)$ & $28 / 125(22)$ \\
Paramedic $(n=115)$ & $23 / 109(21)$ \\
Porter $(n=36)$ & $24(67)$ \\
General technical $(n=17)$ & $6(35)$ \\
Theatre technicians $(n=13)$ & $7(54)$ \\
\hline${ }^{*}$ Clerical staff are distributed throughout medical records,
\end{tabular}

${ }^{\star}$ Clerical staff are distributed throughout medical records, medical equipment and services unit, and catering department. staff thought that guidelines for workplace practices in dealing with patients with AIDS, or with their body fluids, or with contaminated waste were relevant to them. Midwives, nurses, and theatre technicians showed the most awareness of the existence of such guidelines compared with only half of doctors, ambulance, and paramedical staff (table 3). None of the incinerator staff, who deal with disposal of items contaminated with body fluids, reported knowledge of safe working guidelines, although these did exist. Half of staff $(50 \% ; 439 / 880)$, indicated that they had received information about HIV in the workplace. Such information was, however, made available by senior managers to about two thirds of the staff in this study (table 3 ). One in four staff $(25 \% ; 240 / 958)$ indicated that they were not at all satisfied with their current knowledge on safe working practices.

Attitudes to patients with HIV or AIDS - Two thirds of staff considered that patients should be routinely tested for HIV before admission $(62 \%$; 593/958). Although doctors (38\%, $36 / 94)$ and midwives $(11 \%, 1 / 9)$ were significantly less likely to hold this view than all other occupational groups combined $(36 \%$, $37 / 103 v 68 \%, 364 / 532 ; \chi^{2}=37 \cdot 8, \quad \mathrm{df}=1$, $\mathrm{p}<0.001$ ), it is notable that over a third of doctors and half of nurses $(52 \%, 67 / 128)$ held this opinion. One third of staff indicated that, once identified, patients with HIV infection or AIDS should be treated in isolation or in a special ward. Again, though doctors (17\%, $16 / 94)$, midwives (0), and nurses (19\%, 24/128) were significantly less likely to hold this view than all other occupational groups $\left(17 \%, 40 / 231 v 55 \%, 220 / 402 ; \chi^{2}=83 \cdot 3, \mathrm{df}=1\right.$, $\mathrm{p}<0.001)$, the proportion of doctors and nurses with this view was noteworthy.

Perception of risk - In all, $32 \%$ of staff (303/958) indicated that they thought they were at some risk of HIV infection in their occupational setting. Those most likely to perceive themselves as being at risk were midwives $(67 \%, 6 / 9)$ and ambulance staff $(70 \%, 46 / 66)$ (table 4 ); only $23 \%$ of doctors and laboratory workers and $38 \%(48 / 127)$ of nurses considered themselves to be at risk. Unfortunately, sample size of such doctors was too small to analyse the data by specialty. Interestingly, $49 \%(65 / 132)$ of domestic staff and some $32 \%(8 / 25)$ of catering staff thought that there was some occupational risk of HIV infection. When the sample size allowed, perception of risk to self was compared to that to others in the peer group. Domestic staff were significantly more likely to perceive other domestic staff as at greater risk of infection than themselves $(61 \%, 81 / 132 v 49 \%, 65 / 132$; $\chi^{2}=49 \cdot 5, \mathrm{df}=1, \mathrm{p}<0.001$ ) (table 4 ), and similar findings were noted in nurses.

\section{INTERVIEW SURVEY}

Fifteen of the 22 senior managers stated that guidelines for safe working in the context of HIV were available in their department and that information had been disseminated to staff. Two managers, of the catering and physiotherapy departments, indicated that 
Table 3 Number (percentage) of respondents aware of existence of code of practice for safe working and availability of guidelines by occupational group

\begin{tabular}{|c|c|c|c|c|}
\hline \multirow[t]{2}{*}{ Occupational group } & \multicolumn{3}{|c|}{ Code of practice for HIV } & \multirow{2}{*}{$\begin{array}{l}\text { Availability of } \\
\text { guidelines by } \\
\text { managers }\end{array}$} \\
\hline & $\begin{array}{c}\text { Patients with } \\
\text { HIVIAIDs }\end{array}$ & $\begin{array}{l}\text { Body fluids } \\
\text { from patients }\end{array}$ & $\begin{array}{l}\text { Waste material } \\
\text { from patients }\end{array}$ & \\
\hline Ambulance $(n=67)$ & $28 / 66(42)$ & $18 / 64(28)$ & $18 / 64(28)$ & Yes \\
\hline Catering $(n=25)$ & $2(8)$ & $2(8)$ & $2(8)$ & No \\
\hline Clerical $(n=139)$ & $28 / 134(21)$ & $33(24)$ & $32 / 135(24)$ & Not thought appropriate \\
\hline Doctor $^{\star}(n=94)$ & $45 / 92(49)$ & $50(56)$ & $46 / 90(51)$ & Yes \\
\hline Domestic $(n=137)$ & $28 / 135(21)$ & $24 / 136(18)$ & $27 / 135(20)$ & Yes \\
\hline Incinerator $(n=5)$ & 0 & () & () & Yes \\
\hline Laboratory $(n=139)$ & $39(28)$ & $117(84)$ & $74(53)$ & Yes \\
\hline Medical equipment services unit $(n=34)$ & $8 / 33(24)$ & $13 / 35(38)$ & $11 / 33(32)$ & Not thought appropriate \\
\hline Midwife $(n=9)$ & $7(78)$ & $9(100)$ & $9(100)$ & Yes \\
\hline Nurse $(n=128)$ & $95 / 127(75)$ & $95 / 127(75)$ & $95 / 127(75)$ & Yes \\
\hline Paramedic $(n=115)$ & $49(43)$ & $39(34)$ & $34 / 113(31)$ & No \\
\hline Porter $(n=36)$ & $7(19)$ & $8(22)$ & $8(22)$ & Yes \\
\hline General technical $(n=17)$ & $10(59)$ & $9(53)$ & $7(41)$ & Not thought appropriate \\
\hline Theatre technicians $(n=13)$ & $12(92)$ & $12(92)$ & $13(100)$ & Yes \\
\hline
\end{tabular}

^Below consultant.

Table 4 Perception of risk of occupational HIV transmission to self and other occupational groups among respondents. Figures are numbers (percentages)

\begin{tabular}{|c|c|c|c|}
\hline Occupational group & Risk to self & $\begin{array}{l}\text { Risk to doctor } \\
\text { or nurse }\end{array}$ & Risk to domestic \\
\hline Ambulance $(n=67)$ & $46 / 66(70)$ & $30 / 66(46)$ & $30 / 64(47)$ \\
\hline Catering $(n=25)$ & $8(32)$ & $16(64)$ & $14(56)$ \\
\hline Clerical $(n=139)$ & $75 / 132(57)$ & $85 / 129(66)$ & $41 / 132(31)$ \\
\hline Doctor $^{\star}(n=94)$ & $22(23)$ & $27 / 93(29)$ & $13 / 92(14)$ \\
\hline Domestic $(n=137)$ & $65 / 132(49)$ & $92 / 129(71)$ & $81 / 132(61)$ \\
\hline Incinerator $(n=5)$ & $2 / 4(50)$ & $3 / 4(75)$ & $2 / 4(50)$ \\
\hline Laboratory $(n=139)$ & $32 / 138(23)$ & $55 / 138(40)$ & $22 / 138(16)$ \\
\hline Medical equipment services unit $(n=34)$ & $12 / 32(38)$ & $18 / 33(55)$ & $9 / 33(27)$ \\
\hline Midwife $(n=9)$ & $6(67)$ & $4(44)$ & $4(44)$ \\
\hline Nurse $(n=128)$ & $48 / 127(38)$ & $61 / 125(49)$ & $25 / 127(20)$ \\
\hline Paramedic $(n=115)$ & $20 / 113(18)$ & $50 / 112(45)$ & $20 / 113(18)$ \\
\hline Porter $(n=36)$ & $15 / 35(44)$ & $23 / 35(66)$ & $14 / 35(40)$ \\
\hline General technical $(n=17)$ & $3(18)$ & $10(59)$ & $9 / 16(56)$ \\
\hline Theatre technicians $(n=13)$ & $9(69)$ & $10(77)$ & $4(31)$ \\
\hline
\end{tabular}

*Junior to consultant level. managers having made guidelines for safer working practices available to about two thirds of hospital staff across the occupational groupings, except to paramedical, catering, and clerical staff and equipment technicians.

Written guidelines on how to deal with sharps and when to use gloves were available, and senior managers emphasised that these guidelines had been disseminated to appropriate occupational groups, particularly those involved in the clinical management of patients with AIDS. However, although midwives, nurses, and theatre technicians were aware of them, half of the doctors in the survey were not. In addition, although hospital guidelines were available on the disposal of biological waste material, none of the five incinerator staff in the survey were aware of them. There seem therefore important gaps between the existence of guidelines for safe working practices, dissemination of information by senior managers, and awareness of guidelines at staff level. The process of dissemination of information in the hospital across lines of management was outside the scope of this study, although the findings reported here suggest that it should be explored. theder, such occurrences rare. Specific guidelines were deemed to be inappropriate by the managers of clerical, medical equipment, occupational therapy, dietetics, and health care of the elderly staff and were unavailable to these staff. Although hospital guidelines were available for the safe disposal of bodily and other waste, it is notable that none of the incinerator staff reported being aware of them.

\section{Discussion}

This study achieved a good response rate of $63 \%$, comparable to rates of $56 \%,{ }^{9} 63 \%$, $64 \%,{ }^{5}$ and $73 \%{ }^{7}$ in other surveys of related topics in the United Kingdom. Gaps in knowledge, negative attitudes towards patients with AIDS, and perception of risk of occupational infection were, with the exception of midwives, found across all occupational groups, even among doctors and nurses. Overall, one in four staff expressed dissatisfaction with their knowledge about safe working practice, and all groups wanted more information, in common with responders in similar studies. ${ }^{513}$ The need for further information was stated despite senior
KNOWL LEDGE

As reported in previous studies, ${ }^{410}$ knowledge of the ways in which HIV could be transmitted in the workplace, particularly in relation to needlestick injury, was good in doctors, nurses, and across all other occupational groups of staff. However, certain important misconceptions still prevail.

Between one in four and nearly one in three of some groups of non-clinical staff and about one in ten doctors and nurses thought that HIV could be acquired from donating blood. These findings are similar to those reported by Smithson. ${ }^{6}$ The proportion of nurses with this view, at $13 \%$, was considerably lower than the $32 \%$ reported by Akinsanya and Rouse, ${ }^{9}$ but is still of considerable concern. It could be argued that doctors and nurses would be expected to have easiest access to good information on this topic and that they should know that new needles are used to collect blood from each donor.

High proportions of domestic and catering staff thought that HIV could be transmitted 
through sharing cutlery with an infected person, a finding which is particularly relevant in providing accurate information to catering staff, who are responsible for washing patients' cutlery and trays.

Knowledge of appropriate use of gloves in caring for patients with AIDS was also relatively poor, with half of all staff and around a fifth of doctors and nurses (midwives excepted) thinking that gloves should be used during all contacts. Though knowledge of safe working practices is generally unrelated to their uptake 4 and particularly to the use of gloves and universal precautions, ${ }^{8}$ it is important that staff are well informed. Although perhaps not sufficient to change behaviour, improvements in staff knowledge in the short term have been associated with positive changes in attitude towards patients with AIDS. ${ }^{10}$

ATTITUDES

In this study negative attitudes towards patients with AIDS were recorded among large proportions of all staff, but most particularly among those likely to have less contact with such patients, a finding in agreement with other studies. ${ }^{511} 15$ These findings are extremely important in terms of the way in which they might affect the quality of care provided for AIDS patients. ${ }^{13}$ In particular, it was disturbing that about one in five doctors and nurses thought that patients with AIDS should be isolated within the hospital. Within hospitals and the community, doctors and nurses should be acting as peer leaders to promote positive tolerant attitudes towards people with AIDS.

PERCEPTION OF RISK

The perceptions of risk of HIV infection in the workplace we recorded were similar to those reported elsewhere..$^{10}$ Interestingly, significant proportions of domestic and catering staff perceived an occupational risk of infection. Although nursing staff have the task of dealing directly with biological emissions from patients, there may be occasions when domestic staff are in the vicinity of such waste. Uncertainty about how to deal with these situations - for example, when cleaning toilets - could explain why high proportions of domestic staff expressed concern. However, $90 \%$ of these staff knew that they should wear gloves when cleaning toilets or handling any bodily waste from patients. The explanation for workers perceiving themselves at risk in a situation of virtually no risk when they know about safe working practices therefore lies elsewhere, and it may relate to practical working experience. In this study staff with less direct contact with patients with HIV infection and AIDS were significantly more likely to perceive themselves to be at risk. Fear of the unknown and lack of practical experience, coupled with the fact that people find it hard to accept the low probability of an event occurring, ${ }^{19}{ }^{20}$ may all contribute to the findings reported for domestic staff.

Such factors may also explain why one in three catering staff perceived themselves at risk, although the catering manager's observation at interview provides compelling evidence of the experiential basis for that perception. The catering department had no policy guidelines for safe working practices in the context of HIV. Our results suggest the need for such guidelines.

Perception of risk is a complex concept. The findings of this study are nonetheless consistent with aspects of conceptual models posited by researchers in the field. ${ }^{21} 22$ For example, Weinstein noted that an individual subject is more likely to think their chances of experiencing a problem are less than those of their peers. ${ }^{23}$ In this study, for instance, domestic and nursing staff were more likely to rate other domestic and nursing staff respectively as at risk of HIV infection in the workplace. Group views and an individual's perception of them are therefore important in calculating or assessing perceived personal risk. $^{21}$ Such findings have clear implications for interventions and suggest that group discussion and group approaches generally may be important in calculating realistic appreciation of risk and reducing the level of concern about occupational transmission of HIV. Staff training in groups, either within or across occupational boundaries, may also help in exploring negative attitudes towards patients with AIDS and providing accurate information about HIV transmission in the workplace.

\section{Conclusions}

Our findings suggest that policy guidelines for safe working practices in relation to HIV should be made available and disseminated to all hospital staff. Cockroft argued that departments of occupational health have an important role, ${ }^{24}$ and the department in Nottingham has been active in helping the health authority to develop policies. ${ }^{25}$ Our findings, however, seem to indicate that policy guidelines, even with procedures for dissemination and management commitment to the task, are insufficient to deal with gaps in knowledge, poor attitudes towards patients with AIDS, and problems with perception of risk of occupational infection. These complex and interrelated areas probably need to be addressed by staff training programmes which allow group discussion and debate.

Intervention will not be easy and, given the high turnover of staff across all departments, will be a continuing process. We argue that senior managers should not doubt that resolving these issues is relevant to them and should be tackled, even in those geographic areas where the prevalence of AIDS cases is currently relatively low. The identification and implementation of appropriate measures may well have immediate benefits for the quality of care provided for AIDS patients currently in hospital.

We thank the general manager of Queen's Medical Centre, $M$ David Edwards, for his support and advice in developing this study; the hospital staff for taking part, and Kerry Shipston for preparing the manuscript and Mary Stevenson for data entry. 
1 Advisory Committee on Dangerous Pathogens. HIV - the causative agent of AIDS and related conditions. London: HMSO, 1990.

2 Jefferies DJ. Doctors, patients, and HIV. BMF 1992;304:1258-9.

3 UK Departments of Health. Guidance for clinical health care workers: protection against infection with HIV and hepatitis viruses. London: HMSO, 1991.

4 Brattebo G, Wisborg T, Sjursen $\mathrm{H}$. Health workers and the human immunodeficiency virus: knowledge, ignorance and behaviour. Public Health 1990;104:123-30.

5 Klimes I, Catalan J, Bond A, Day A. Knowledge and attitudes of health care staff about HIV infection in a health district with low HIV prevalence. AIDS Car 1989;1:313-7.

6 Smithson RD. Public and health staff knowledge about AIDS. Community Med 1988;10:221-7.

7 Bond S, Rhodes T, Philips P, Setters J, Foy C, Bond J. HIV infection and AIDS in England: the experience, knowledgo infection and AIDS in England: the experience, knowledgo
and intentions of community mursing staff. Newcastle upon and intentions of community mursing staff. Newcastle upon Newcastle upon Tyne, 1990

8 Talan DA, Baraff LJ. Effect of education on the use of universal precautions in a university hospital emergency department. Ann Emerg Med 1996;19:1322-6.

9 Akinsanya JA, Rouse P. Who will care? A survey of knowledgc and attitudes of hospital nurses to people with HIV/AIDS London: HMSO, 1991

10 McKinnon $\mathrm{MD}$, Insall $\mathrm{C}$, Gooch $\mathrm{CD}$, Cockroft $\mathrm{A}$ Knowledge and attitudes of health care workers about AIDS and HIV infection before and after distribution of an education booklet. F Soc Occup Med 1990; 40: of an $15-8$.

11 Gallop RM, Lancee WJ, Taerk G, Coates RA, Fanning M. Fear of contagion and AIDS: nurses' perception of risk. AIDS Care 1992;4:103-9.

12 Wallack JJ. AIDS anxiety among health care professionals. Hospital Community Psychiatry 1989;40:7-510.

13 Pleck JH, O'Donnell L, O'Donnell C, Snarey J. AIDS phobia, contact with AIDS and AIDS-related job stress in hospital workers. $\mathcal{f}$ Homosex 1988;15:41-55.

14 Blumenfield M, Smith PJ, Milazzo J, Seropian S, Wormser GP. Survey of attitudes of nurses working with AIDS patients. Gen Hosp Psychiatry 1987;9:58-63.

15 Barrick B. The willingness of nursing personnel to care for patients with acquired immunodeficiency syndrome: a patients with acquired immunodeficiency syndrome: a $1988: 4: 366-72$

16 World Health Organisation. Report of a WHO consultation (1) the prezention of human immunodeficiency rimus transmission in a health care setting. Geneva: WHO, 1991. (Global Programme on AIDS.)

17 UK Central Council for Nursing, Midwifery and Health Visiting. Council position stutement. London: UKCCNMHV, 1992.

18 Davidson G. Policy perception and prevention of HIV transmission in a hospital context [BMedSci thesis]. Nottingham: Department of Public Health Medicine and Epidemiology, University of Nottingham.

19 Hershey J, Baron J. Clinical reasoning and cognitive process. Med Decis Making 1987;7:203-11.

20 Derber RA, Goel V. Using explicit decision rules to manage issues of justice risk and ethics in decision analysis: when is it not rational to maximise expected utility? Med Decis Making 1990;10:181-94

21 Weinstein ND. Perceptions of personal susceptibility to harm. In: Mays V, Albee GW, Scheider SF, eds. Primary prevention of AIDS: pswchological approaches. New York: Sage, 1989 ;

22 Kulik JA, Mahler HIM. Health status, perceptions of risk and prevention interest for health and non-health problems. Health Psychol 1987;6:15-27.

23 Weinstein ND Why it won't happen to me: perceptions of risk factors and illness susceptibility. Health Psvchol 1984;3:431 57

24 Cockroft A. AIDS/HIV infection and employment: the role of occupational health services. If Soc (cicup Med 1989;39:49-50.

25 Nottingham Health Authority Anmul report (AII)S Control Act 1987). Nottingham: NHA, 1991. 